\title{
Dielectric Permittivity and Viscoelastic Measurements of Two Tricomponent Mixtures Consisting of Laterally Fluorinated Terphenyl Derivatives
}

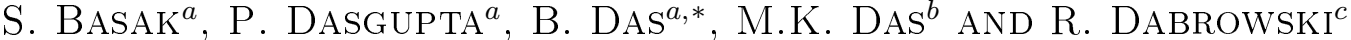 \\ ${ }^{a}$ Department of Physics, Siliguri Institute of Technology, Siliguri, Darjeeling - 734009, India \\ ${ }^{b}$ Department of Physics, University of North Bengal, Siliguri, Darjeeling - 734 013, India \\ ${ }^{c}$ Department of Advanced Technologies and Chemistry, Military University of Technology \\ 00-908 Warsaw, Poland
}

(Received April 14, 2012; in final form November 5, 2012)

\begin{abstract}
Two tricomponent room temperature nematic eutectic mixtures $\mathrm{ABC}$ and $\mathrm{ABD}$ with laterally fluorinated constituents A and B were prepared as base mixtures for vertically aligned mode LCD's. The physical properties of these mixtures viz. birefringence, dielectric anisotropy, bend elastic constant, relaxation time and rotational viscosities were determined in order to compare with the optimum values required to achieve the target specifications of VA mode materials. The dielectric anisotropy, $\Delta \varepsilon$, and optical birefringence, $\Delta n$, of these mixtures were found to be in the range of $(-1.3$ to -1.4$)$ and $(0.13$ and 0.14$)$, respectively, at around $20^{\circ} \mathrm{C}$. The figure of merit for the $\mathrm{ABD}$ mixture has been found to be higher than that of $\mathrm{ABC}$ mixture throughout the entire temperature range. The pretilt angle effect in the physical parameters has also been studied. At $T=20^{\circ} \mathrm{C}$, the response time decreases to $25 \%$ and $35 \%$ for mixture $\mathrm{ABC}$ for $2^{\circ}$ and $5^{\circ}$ pretilt respectively in comparison to zero pretilt. On the other hand, at the same temperature for the ABD mixture these values are reduced by $16 \%$ and $35 \%$, respectively.
\end{abstract}

DOI: 10.12693/APhysPolA.123.714

PACS: 61.30.-v, 78.20.Fm, 87.19.rd, 87.19.rf, 83.60.Bc

\section{Introduction}

Development of liquid crystal materials with optimum physical properties is essential for their application in liquid crystal display (LCD) devices. The performance of liquid crystal materials in LCD's depends critically on the temperature dependence of the dielectric, optical, elastic constants and rotational viscosity of the materials to be used. In continuation of our earlier work on two tricomponent mixtures ( $\mathrm{ABC}$ and $\mathrm{ABD}$ ) as base mixtures for vertically aligned (VA) mode LCD's [1-3], where we had reported the orientational order parameters from optical birefringence and X-ray diffraction measurements [4], in this paper, we report the results of the dielectric permittivity, bend elastic constant and rotational viscosity measurements on these mixtures at the eutectic composition throughout their entire mesomorphic range. Vertically aligned mode applications require liquid crystalline materials with negative dielectric anisotropy $[5,6]$. Such features are realized with liquid crystals having lateral polar substituents which induce a dipole moment perpendicular to the long axes of the molecule [7]. Furthermore, the birefringence, $\Delta n$, has also to be adjusted to fit the precise display configuration. For currently used cell gaps $(\approx 4 \mu \mathrm{m})$, the required birefringence values for vertically aligned materials must be around 0.08 [8]. In addition, the elastic constants also influence the operating voltage. The rotational viscosity $\gamma_{1}$ should be as low as possi-

*corresponding author; e-mail: banbuin@yahoo.com ble to allow fast switching. Since, no single liquid crystal material can fulfill all the above-mentioned requirements, multi-component mixtures are used to achieve the specific requirement.

In this work, the results of the material parameters including birefringence, dielectric anisotropy, bend elastic constant, relaxation time and rotational viscosities of the $\mathrm{ABC}$ and $\mathrm{ABD}$ tricomponent system have been reported. Moreover, the dependence of the threshold voltage as well as the relaxation time, which has important implications on the performance of the display device, of these two mixtures have been studied using various pretilted cells $\left(2^{\circ}\right.$ and $5^{\circ}$ pretilt $)$ and the results have been compared with the physical properties of the mixtures with zero-pretilt cells. The selective pretilting reduces the apparent tilt angle, i.e., the angle between the projections onto the substrate plate of the nematic layer normal and the director in the uniform states, which has a better effect on switching time, threshold voltage and the display contrast [9].

\section{Experimental}

\subsection{Materials}

As reported by us earlier, four compounds constituting the main components of the mixture for vertical alignment were chosen. Two tricomponent systems, ABC and ABD comprising of laterally fluorinated dielectrically negative terphenyl derivatives and one bicyclohexane component were studied [4]. The chemical structure and transition temperatures of the four pure compounds are shown in Table I. 
TABLE I

Chemical structure and transition temperatures of the pure components of the vertical alignment mixtures.

\begin{tabular}{cc|c|c}
\hline Compound \& Structure & $T_{\mathrm{m}}\left[{ }^{\circ} \mathrm{C}\right]$ & $T_{\mathrm{NI}}\left[{ }^{\circ} \mathrm{C}\right]$ \\
\hline
\end{tabular}

Molar composition of the pure components and comparison of the theoretical and experimental eutectic points.

\begin{tabular}{|c|c|c|c|c|}
\hline Mixtures & Comp. & Mole ratio & Theoretical & Experimental \\
\hline \multirow{3}{*}{$\mathrm{A}+\mathrm{B}+\mathrm{C}$} & $\mathrm{A}$ & 0.386 & \multirow{3}{*}{$\begin{array}{c}T_{\mathrm{m}}=3.7^{\circ} \mathrm{C} \\
T_{\mathrm{c}}=102.1^{\circ} \mathrm{C}\end{array}$} & \multirow{3}{*}{$\begin{array}{l}T_{\mathrm{m}}=11.7^{\circ} \mathrm{C} \\
T_{\mathrm{c}}=97.5^{\circ} \mathrm{C}\end{array}$} \\
\hline & B & 0.269 & & \\
\hline & C & 0.346 & & \\
\hline \multirow{3}{*}{$\mathrm{A}+\mathrm{B}+\mathrm{D}$} & A & 0.491 & \multirow{3}{*}{$\begin{array}{l}T_{\mathrm{m}}=12.4^{\circ} \mathrm{C} \\
T_{\mathrm{c}}=104.6{ }^{\circ} \mathrm{C}\end{array}$} & \multirow{3}{*}{$\begin{array}{l}T_{\mathrm{m}}=15.4^{\circ} \mathrm{C} \\
T_{\mathrm{c}}=100.5^{\circ} \mathrm{C}\end{array}$} \\
\hline & B & 0.354 & & \\
\hline & $\mathrm{D}$ & 0.156 & & \\
\hline
\end{tabular}

The molar ratios of the individual components at the eutectic composition were theoretically estimated by solving the Schröder-van Laar equation [10, 11] and are shown in Table II. As reported by us earlier [4], both the theoretical as well as the experimental eutectic points for the tricomponent mixtures has been compared (Table II) and are found to be in reasonably good agreement with each other.

\subsection{Dielectric permittivity and bend elastic constant measurement}

The static dielectric permittivities $\varepsilon_{\|}$and $\varepsilon_{\perp}$ along and perpendicular to the molecular long axis respectively, and hence the dielectric anisotropy $\Delta \varepsilon\left(=\varepsilon_{\|}-\varepsilon_{\perp}\right)$ were measured at $1 \mathrm{kHz}$ by measuring the capacitance of a liquid crystal cell (thickness $8.9 \mu \mathrm{m}$ ) using Agilent E4980A digital LCR-bridge. The liquid crystalline material was filled inside a homeotropically aligned cell procured from AWAT PPW, Warsaw, Poland. The cell was mounted inside an electrically powered thermostat-block, the temperature of which was controlled within an accuracy of $\pm 0.1^{\circ} \mathrm{C}$ by a temperature controller (Eurotherm PID 2404). The temperature variation of the principal dielectric permittivities $\varepsilon_{\|}$and $\varepsilon_{\perp}$ were measured. The details of the experimental procedure for determining the dielectric permittivities have been reported by us earlier [12]. For bend elastic constant $\left(K_{33}\right)$ measurement, a sinusoidal voltage upto $20 \mathrm{~V}_{\mathrm{rms}}$, at $1 \mathrm{kHz}$, was applied and the cell capacitance as a function of the applied voltage was recorded. The voltage step was $20 \mathrm{mV}_{\mathrm{rms}}$ in the vicinity of the electric field induced Freedericksz transition [13] and $200 \mathrm{mV}_{\mathrm{rms}}$ in the higher voltage region. The critical electric field for the Freedericksz transition could be observed quite accurately (within $0.5 \%$ ) from the sudden change in the capacitance value. The bend elastic constant $K_{33}$ was calculated from the well known equation [13]:

$$
K_{33}=\frac{\varepsilon_{0} \Delta \varepsilon V_{\mathrm{th}}^{2}}{\pi^{2}}
$$

where $\varepsilon_{0}$ is the permittivity of free space and $V_{\text {th }}$ is the critical field in rms.

\subsection{Refractive indices measurement}

The principal refractive indices $\left(n_{\mathrm{o}}, n_{\mathrm{e}}\right)$ for wavelength $\lambda=632.8 \mathrm{~nm}$ were measured within an accuracy of \pm 0.0004 by thin prism method as reported by Prasad and Das [14]. The temperature of the prism was controlled using a specially constructed heater and a temperature controller (Eurotherm PID 2404) with an accuracy of $\pm 0.1{ }^{\circ} \mathrm{C}$.

\subsection{Rotational viscosity measurement}

We report a relaxation method in which the time decay of the optical phase retardation of the liquid crystal cell was used to determine the rotational viscosity [15]. When a small voltage is applied to a homeotropically aligned liquid crystal cell the nematic directors are deformed by a small angle. At time $t=0$, this voltage is removed and the molecules relax with relaxation time $\tau_{0}$ to the equilibrium state. For a liquid crystalline slab of thickness $d, \tau_{0}$ is related to the material parameters by

$$
\gamma_{1}=\frac{\tau_{0} K_{33} \pi^{2}}{d^{2}}
$$

where $K_{33}$ is the bend elastic constant coefficient and $\gamma_{1}$ the rotational viscosity of the liquid crystalline material. The details of experimental technique and data analysis have been reported by us in our earlier publication [16].

\section{Results and discussion}

\subsection{Dielectric anisotropy}

The variation of dielectric permittivities $\varepsilon_{\|}$and $\varepsilon_{\perp}$ for the two tricomponent mixtures $\mathrm{ABC}$ and $\mathrm{ABD}$ as a function of temperature is shown in Fig. 1. The dielectric constant in the isotropic phase obtained from two different geometries matches within $0.5 \%$. $\varepsilon_{\perp}$ is larger than $\varepsilon_{\|}$throughout the nematic phase for the two mixtures. Therefore, both the mixtures exhibit negative dielectric anisotropy. There is a sharp discontinuity in the permittivity components for both the mixtures at the nematic-isotropic transition $\left(T_{\mathrm{NI}}\right)$. However, the dielectric anisotropy, $\Delta \varepsilon$ for mixture $\mathrm{ABD}$ is slightly higher than those obtained from $\mathrm{ABC}$ (Fig. 2) and its value is about -1.4 around $20^{\circ} \mathrm{C}$.

\subsection{Optical birefringence}

Results of our optical birefringence measurements were reported in our earlier publication [4]. Optical transmission method was used to determine temperature dependence of the birefringence values. However, such measurement is based on several assumptions. In this paper, 


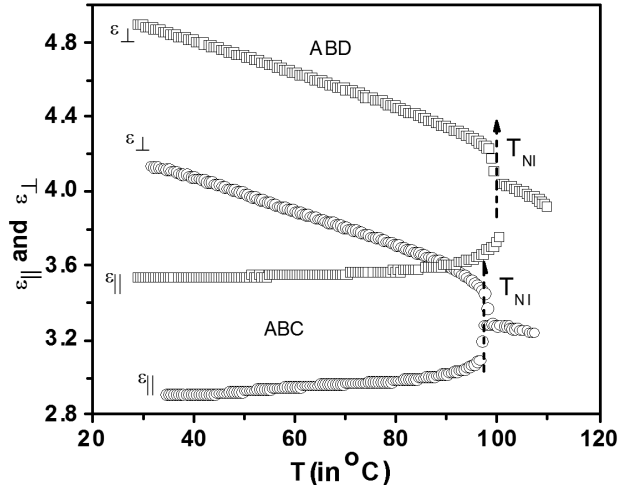

Fig. 1. Variation of the dielectric permittivities $\varepsilon_{\|}$and $\varepsilon_{\perp}$ with temperature (cell gap $=8.9 \mu \mathrm{m}$ ) for mixtures $\mathrm{ABC}$ and $\mathrm{ABD}$. Key to symbols: $\circ$ mix $\mathrm{ABC}$; $\square$ mix ABD. $T_{\mathrm{NI}}=$ nematic - isotropic transition temperature.

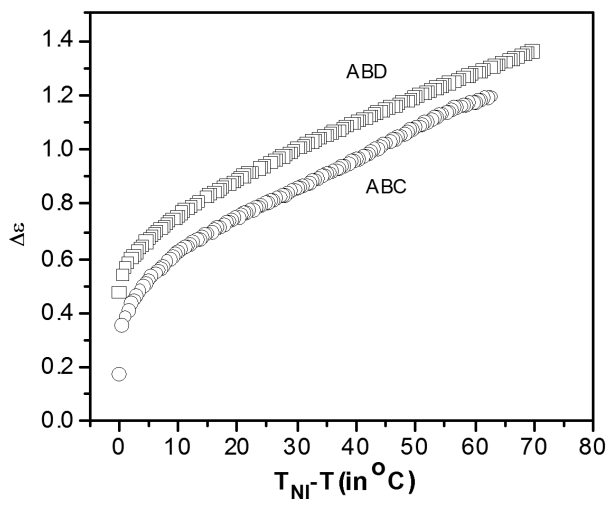

Fig. 2. Variation of dielectric anisotropy, $\Delta \varepsilon$, with temperature $T_{\mathrm{NI}}-T$ (cell gap $=8.9 \mu \mathrm{m}$ ) for mixtures $\mathrm{ABC}$ and $\mathrm{ABD}$. Key to symbols: $\circ$ mix $\mathrm{ABC}$; $\square \operatorname{mix} \mathrm{ABD}$.

the principal refractive indices $\left(n_{\mathrm{o}}, n_{\mathrm{e}}\right)$ for wavelength $\lambda=632.8 \mathrm{~nm}$ were also measured within \pm 0.0004 by thin prism method (Fig. 3). The birefringence values obtained from thin prism method are shown in Fig. 4. The values of $\Delta n$ determined from optical transmission are found to be around 3\% higher than those measured by thin prism method, possibly due to the fact that the surface anchoring is much better in thin cells $(8.9 \mu \mathrm{m})$ in comparison to thin prisms (thickness $200-400 \mu \mathrm{m}$ ) which thereby retains the monodomain alignment almost throughout the mesomorphic range except very near the $T_{\mathrm{NI}}$ transition. Such higher values of $\Delta n$ in the transmission method of thin samples have been reported by us previously [14] and also have been reported by others [17].

Upon switching, the reorientation of the liquid crystal molecules leads to an effective change of the optical path which is defined as the product $d \Delta n$ [8]. Generally the optical path lengths $d \Delta n$ for the VA mode displays are as low as $0.20-0.35 \mu \mathrm{m}, d$ being the liquid crystal cell thickness [18], which leads to $\Delta n$ values of around 0.08 for currently used cell gaps $(d=4 \mu \mathrm{m})$. It may be pointed

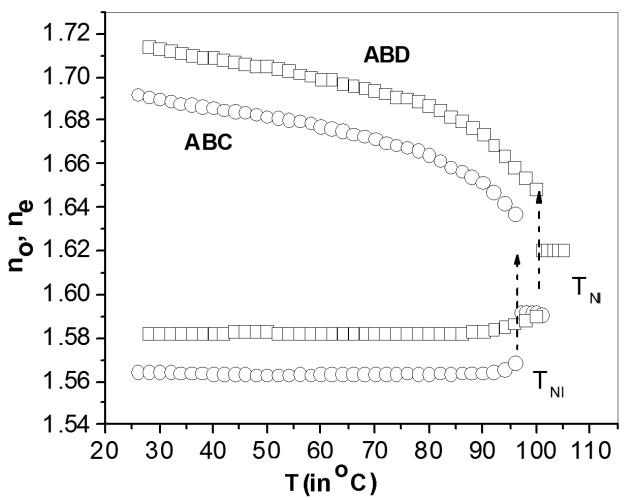

Fig. 3. Variation of $n_{\mathrm{o}}, n_{\mathrm{e}}$ values with temperature for mixtures $\mathrm{ABC}$ and $\mathrm{ABD}$ using thin prism method. Key to symbols: $\circ \operatorname{mix} \mathrm{ABC}$; $\square \operatorname{mix} \mathrm{ABD} . T_{\mathrm{NI}}=$ nematic isotropic transition temperature.

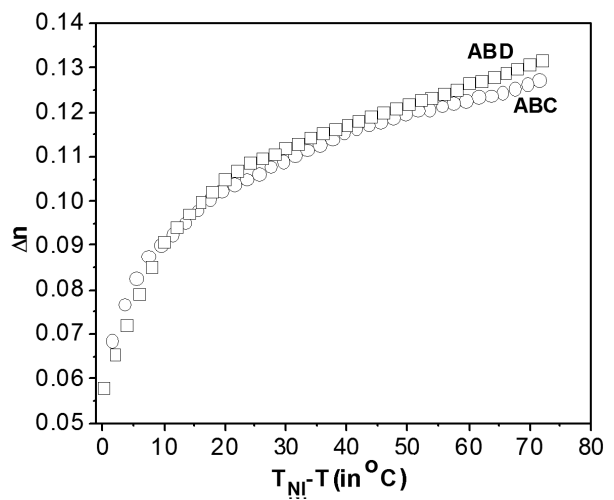

Fig. 4. Variation of birefringence $\left(\Delta n=n_{\mathrm{e}}-n_{\mathrm{o}}\right)$ with temperature $T_{\mathrm{NI}}-T$ for mixtures $\mathrm{ABC}$ and $\mathrm{ABD}$. Key to symbols: $\circ$ mix ABC; $\square$ mix ABD.

out that, as observed from Fig. 4, the birefringence values for both the mixtures ABC and ABD are nearly the same and are found to be around 0.129 and 0.135 , respectively, at $20^{\circ} \mathrm{C}$ which is fairly close to the targeted specification for VA mode mixtures.

\subsection{Bend elastic constant $\left(K_{33}\right)$}

The temperature dependence of the bend elastic constant $K_{33}$ for mixtures $\mathrm{ABC}$ and $\mathrm{ABD}$ are shown in Fig. 5. It is found that the $K_{33}$ values in ABD is smaller in the entire nematic range compared to that of $\mathrm{ABC}$. A smaller elastic constant is favourable to achieve a low operating voltage, but it also leads to a slower response time, since response time is proportional to $1 / K_{33}$. In practical cases, response time is usually more important than threshold voltage. As mention in the earlier section, the dielectric anisotropy values for ABD are slightly higher than those of ABC (Fig. 2). However, the Freedericksz threshold, $V_{\text {th }}$ (which is observed at a higher voltage $\approx 2-3 \mathrm{~V}$ ), for ABD are slightly smaller than those of $\mathrm{ABC}$. The resultant effect is to reduce the $K_{33}$ values for $\mathrm{ABD}$ compared to $\mathrm{ABC}$. 


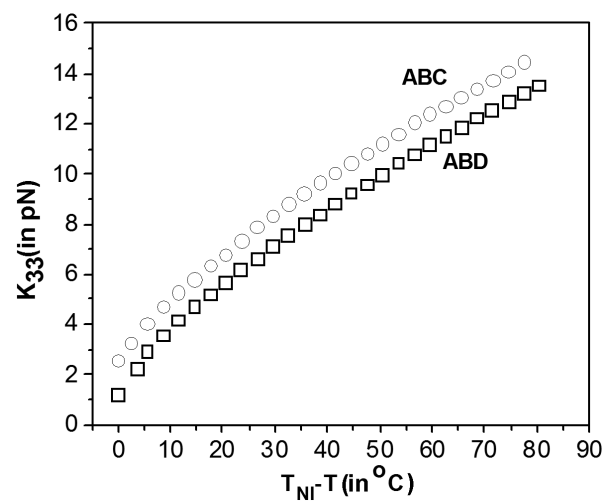

Fig. 5. Variations of the bend elastic constant $\left(K_{33}\right)$ as functions of temperature $T_{\mathrm{NI}}-T($ cell gap $=8.9 \mu \mathrm{m})$ for mixtures $\mathrm{ABC}$ and $\mathrm{ABD}$. Key to symbols: $\circ$ mix $\mathrm{ABC} ; \square \operatorname{mix} \mathrm{ABD}$.

\subsection{Relaxation time and rotational viscosities}

Figure 6 shows the temperature dependence of relaxation time of both the mixtures $\mathrm{ABC}$ and $\mathrm{ABD}$. The re-

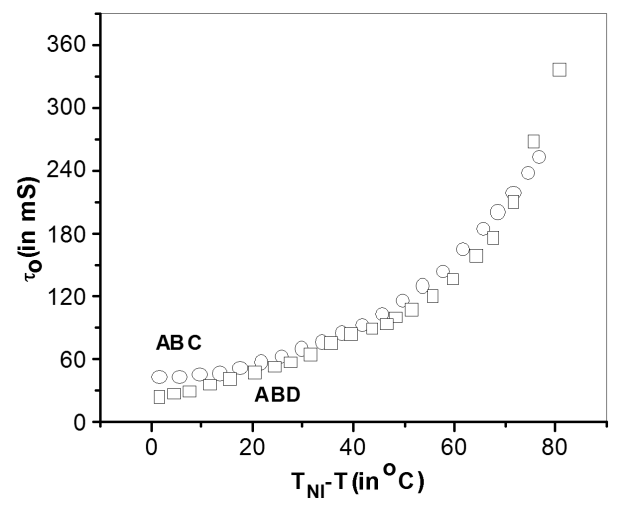

Fig. 6. Variation of relaxation time $\left(\tau_{0}\right)$ with temperature $T_{\mathrm{NI}}-T$ (cell gap $=8.9 \mu \mathrm{m}$ ) for mixtures $\mathrm{ABC}$ and ABD. Key to symbols: $\circ$ mix ABC; $\square$ mix ABD.

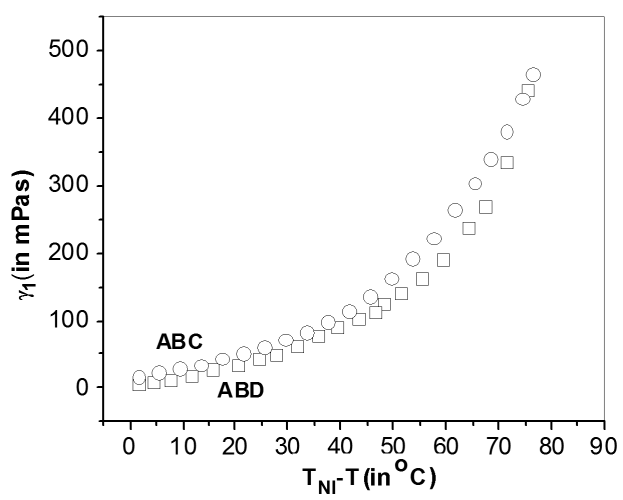

Fig. 7. Variation of rotational viscosity $\left(\gamma_{1}\right)$ with temperature $T_{\mathrm{NI}}-T$ (cell gap $\left.=8.9 \mu \mathrm{m}\right)$ for mixtures $\mathrm{ABC}$ and ABD. Key to symbols: $\circ$ mix ABC; $\square$ mix ABD. laxation time for $\mathrm{ABD}$ is slightly lower than that of $\mathrm{ABC}$. But the temperature dependence of $\tau_{0}$ is sharp in ABD and hence $\tau_{0}$ values at lower temperature for ABD are higher. Both the relaxation time and bend elastic constant was used to calculate the rotational viscosity of the two mixtures and the temperature dependence of the rotational viscosities of the mixtures $\mathrm{ABC}$ and $\mathrm{ABD}$ is shown in Fig. 7. The rotational viscosity of mixture ABD is slightly lower compared to the mixture ABC. However, far away from the clearing temperature the two values appear to be the same.

\subsection{Figure-of-merit}

To assess the overall performance of LC materials, the figure-of-merit (FOM) is determined, which is related to the birefringence and response time as [19]:

$$
\mathrm{FOM}=\frac{\Delta n^{2}}{\gamma_{1} / K_{33}},
$$

where $K_{33}$ is the bend elastic constant, $\Delta n$ is the birefringence, $\gamma_{1}$ is the rotational viscosity. As all of these parameters are temperature dependent accordingly, the figure of merit strongly depends on the temperature. The temperature-dependent figure of merit for ABC and ABD are depicted in Fig. 8. At low-temperature region, even

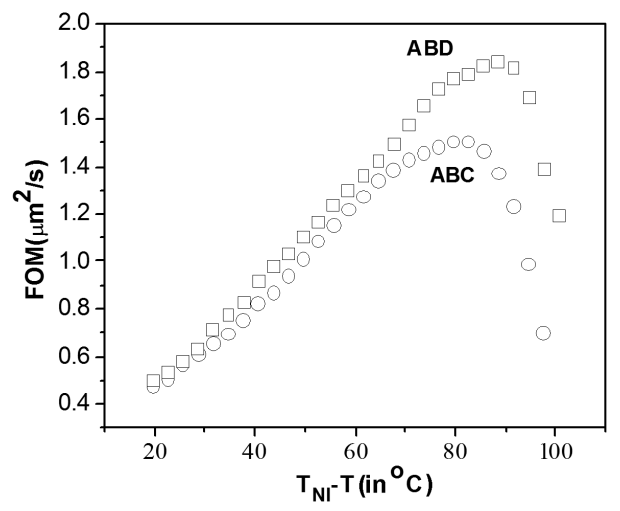

Fig. 8. Variation of figure-of-merit with temperature $T_{\mathrm{NI}}-T($ cell gap $=8.9 \mu \mathrm{m})$ for mixtures $\mathrm{ABC}$ and ABD. Key to symbols: $\circ$ mix ABC; $\square$ mix ABD.

though birefringence, dielectric anisotropy, elastic constants and viscosity all decrease as the temperature increases, the change of viscoelastic coefficient $\left(\gamma_{1} / K_{33}\right)$ with temperature is faster than that of $\Delta n^{2}$. Therefore the figure-of-merit at first increases with increasing temperature and reaches a maximum value at a temperature $T_{\mathrm{NI}}-T \approx 80^{\circ} \mathrm{C}$. As the temperature approaches the clearing temperature $T_{\mathrm{NI}}$, the birefringence has a very steep drop as observed from Fig. 4, which causes a sharp decrease in the figure of merit. The higher figure of merit a LC possesses, the faster response time it exhibits. Thus operating a LC device at an elevated temperature is beneficial for reducing response time. However, it brings complication to the driving scheme by the additional temperature control system. It has been found that throughout 
the temperature range the $\mathrm{FOM}$ for $\mathrm{ABD}$ is higher than that of $\mathrm{ABC}$.

\subsection{Activation energy}

The temperature dependence of $\gamma_{1}$ is fitted with the following expression using the values of the orientational order parameter, $S$, determined from X-ray diffraction measurement [4]:

$$
\gamma_{1}=\gamma_{0} S \exp \left(\frac{E_{\mathrm{a}}}{k_{\beta} T}\right),
$$

where $k_{\beta}$ is the Boltzmann constant and $E_{\mathrm{a}}$ is the associated activation energy [20]. The activation energies thus obtained for two different compositions are $7.62 \mathrm{kcal} / \mathrm{mol}$ and $8.02 \mathrm{kcal} / \mathrm{mol}$, respectively, for mixtures $\mathrm{ABC}$ and ABD (Table III).

\section{TABLE III}

Activation energies $\left(E_{\mathrm{a}}\right)$ for mixtures $\mathrm{ABC}$ and $\mathrm{ABD}$ in $\mathrm{kcal} / \mathrm{mol}$.

\begin{tabular}{c|c}
\hline \hline Mixtures & $E_{\mathrm{a}}[\mathrm{kcal} / \mathrm{mol}]$ \\
\hline $\mathrm{A}+\mathrm{B}+\mathrm{C}$ & 7.62 \\
$\mathrm{~A}+\mathrm{B}+\mathrm{D}$ & 8.02
\end{tabular}

\subsection{Effect of pretilt}

Pretilt angle effect is found to make an important contribution to the liquid crystal dynamics [21]. In a VA cell, the pretilt angle $(\alpha)$ affects the device contrast ratio and response time. The pretilt angle is defined as the angle of the LC directors deviated from cell normal. For $\alpha=0$, it implies that the LC directors are aligned per-

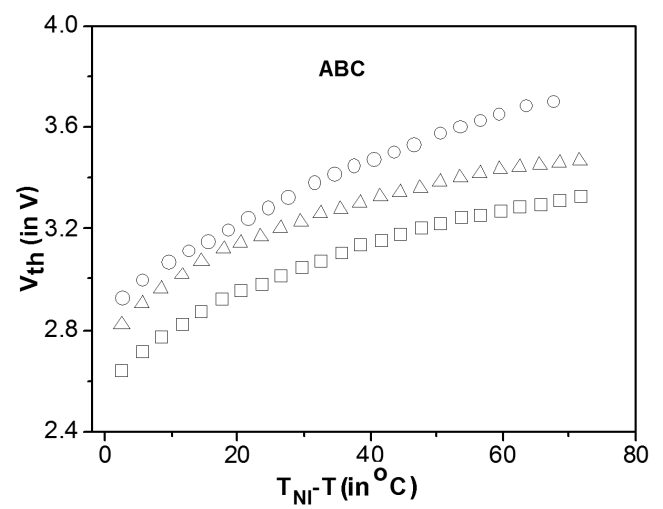

Fig. 9. Variations of threshold voltage $\left(V_{\mathrm{th}}\right)$ as functions of temperature $T_{\mathrm{NI}}-T$ (cell gap $=5 \mu \mathrm{m}$ ) for mixture ABC: pretilt angles $\circ=0^{\circ} ; \Delta=2^{\circ}$ and $\square=5^{\circ}$.

pendicular to the substrate surfaces. As the pretilt angle deviates from the cell normal, the Freedericksz threshold voltage is gradually decreased and hence the operating voltage is reduced (Figs. 9 and 10). In fact, in a real LC device a small pretilt angle is required for LC directors to relax back without creating domains [22].

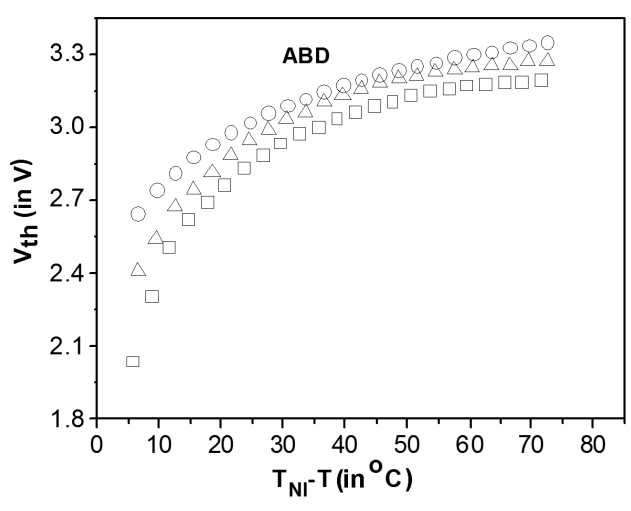

Fig. 10. Variations of threshold voltage $\left(V_{\mathrm{th}}\right)$ as functions of temperature $T_{\mathrm{NI}}-T$ (cell gap $=5 \mu \mathrm{m}$ ) for mixture ABD: pretilt angles $\circ=0^{\circ} ; \triangle=2^{\circ}$ and $\square=5^{\circ}$.

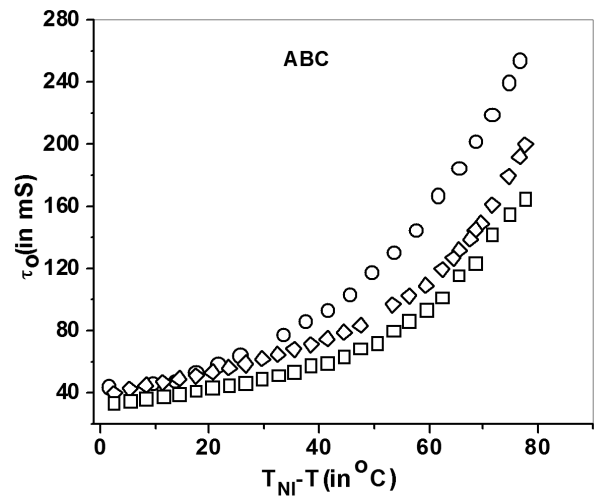

Fig. 11. Variation of relaxation time $\left(\tau_{0}\right)$ with temperature $T_{\mathrm{NI}}-T$ (cell gap $\left.=5 \mu \mathrm{m}\right)$ for mixture ABC: pretilt angles $\circ=0^{\circ} ; \diamond=2^{\circ}$ and $\square=5^{\circ}$.

In Figs. 11 and 12 we plot the relaxation time as a function of temperature at $\alpha=0^{\circ}, 2^{\circ}$ and $5^{\circ}$ pretilt angles for $\mathrm{ABC}$ and $\mathrm{ABD}$, respectively. In general, at a given temperature a smaller pretilt angle would lead to a slower response time. As the pretilt angle increases the response time gradually decreases. In fact at $T=20^{\circ} \mathrm{C}$ the response time decreases to $25 \%$ and $35 \%$ for mixture $\mathrm{ABC}$ for $2^{\circ}$ and $5^{\circ}$ compared to zero pretilt. On the other hand, at the same temperature for $\mathrm{ABD}$, the reductions in these values are $16 \%$ and $35 \%$, respectively. It may be mentioned that increasing $\alpha$ means sacrificing the quality of the state, since the dark state becomes more birefringent. Thus from the manufacturer point of view, a vertically aligned nematic (VAN) displays a delicate balance between response time and contrast has to be maintained. Indeed in nematic liquid crystal displays, a slightly pretilted alignment is playing an important role to eliminate orientational defects which further helps us to improve the device quality [23]. VAN materials are characterized by a negative dielectric anisotropy, which means that the $\mathrm{LC}$ molecules will tend to orient perpendicularly to any applied electric field. However 


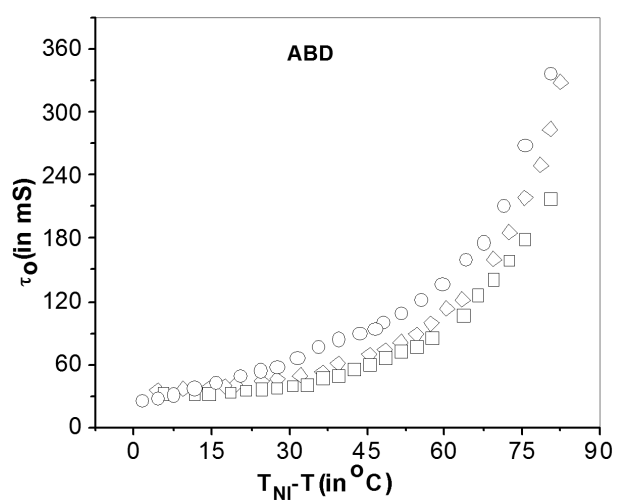

Fig. 12. Variation of relaxation time $\left(\tau_{0}\right)$ with temperature $T_{\mathrm{NI}}-T$ (cell gap $=5 \mu \mathrm{m}$ ) for mixture ABD: pretilt angles $\circ=0^{\circ} ; \diamond=2^{\circ}$ and $\square=5^{\circ}$.

the pretilt has also a drawback - the relaxed state becomes birefringent, and the contrast decays dramatically as pretilt increases. Therefore, choosing a precise pretilt is an important tradeoff when designing real VAN displays $[24,25]$.

\section{Summary and conclusions}

The physical properties of two tricomponent room temperature nematic mixtures $\mathrm{ABC}$ and $\mathrm{ABD}$ with laterally fluorinated constituents A and B for VA mode application are reported. The dielectric anisotropy, $\Delta \varepsilon$ and optical birefringence, $\Delta n$, of these mixtures are in the range of $(-1.3$ to -1.4$)$ and $(0.13$ and 0.135$)$, respectively, at around $20^{\circ} \mathrm{C}$, which are still quite short of the targeted values for VA mixtures. The bend elastic constant, $K_{33}$, values for $\mathrm{ABD}\left(13.5 \mathrm{pN}\right.$ at $\left.20^{\circ} \mathrm{C}\right)$ is smaller in the entire nematic range compared to that of $\mathrm{ABC}(14.5 \mathrm{pN}$ at $20^{\circ} \mathrm{C}$ ). It has been found that throughout the temperature range the FOM for ABD is higher than that of $\mathrm{ABC}$. Moreover, the pretilt angle effect in physical parameters is also studied. At a temperature $T=20^{\circ} \mathrm{C}$ the response time decreases to $25 \%$ and $35 \%$ for mixture $\mathrm{ABC}$ for $2^{\circ}$ and $5^{\circ}$ compared to zero pretilt. On the other hand, at the same temperature for ABD these values are reduced by $16 \%$ and $35 \%$, respectively. Investigations on further improvements in the material properties of these mixtures by the addition of suitable dopants are in progress.

\section{Acknowledgments}

Financial support from Department of Science and Technology, New Delhi (project No: SR/S2/CMP-29/ 2007) to B.D. and financial support from Department of Science and Technology, New Delhi (Project No: SR/S2/ CMP-20/2005) to M.K.D. are gratefully acknowledged.

\section{References}

[1] C.Y. Xiang, X.W. Sun, X.J. Yin, J. Phys. D: Appl. Phys. 37, 994 (2004).

[2] D.S. Seo, Liq. Cryst. 27, 1147 (2000).

[3] M.F. Schiekel, K. Fahrenschon, Appl. Phys. Lett. 19, 391 (1971).

[4] S. Basak, P. Dasgupta, B. Das, M.K. Das, R. Dabrowski, Acta Phys. Pol. A 120, 1037 (2011).

[5] P. Kirsch, M. Bremer, Angew. Chem. 112, 4384 (2000).

[6] P. Kirsch, M. Bremer, Angew. Chem. Int. Ed. 39, 4216 (2000).

[7] V. Reiffenrath, J. Krause, H.J. Plach, G. Weber, Liq. Cryst. 5, 159 (1989).

[8] D. Pauluth, K. Tarumi, J. Mater. Chem. 14, 1219 (2004).

[9] B. Cerrolaza, M.A. Geday, X. Quintana, J.M. Oton, J. Display Technol. 7, 141 (2011).

[10] E.C.H. Hsu, J.F. Johnson, Mol. Cryst. Liq. Cryst. 20, 177 (1973).

[11] I. Schröder, Z. Phys. Chem. 11, 449 (1893).

[12] A. Prasad, M.K. Das, Phys. Scr. 84, 015603 (2011).

[13] V. Freedericksz, V. Tsvetkov, Phys. Z. Sov. Union 6 , (1933).

[14] A. Prasad, M.K. Das, J. Phys., Condens. Matter. 22, 195106 (2010).

[15] M.L. Dark, M.H. Moore, D.K. Shenoy, R. Shashidhar, Liq. Cryst. 33, 67 (2006).

[16] A. Prasad, M.K. Das, Mol. Cryst. Liq. Cryst. 540 162 (2011).

[17] S. Dhara, N.V. Madhusudana, Phase Transit. 81 , 561 (2008).

[18] G. Lussem, M. Bremer, C. Hock, H. Ichinose, P. Krisch, D. Klement, K. Tarumi, in: Proc. 21st Asia Display, IDW, Nagoya 2001, p. 25.

[19] S. Gauza, M. Jiao, S.T. Wu, P. Kula, R. Dabrowski, X. Liang, Liq. Cryst. 35, 1401 (2008).

[20] W.H. De Jeu, Physical Properties of Liquid Crystalline Material, Gordon and Breach, New York 1980.

[21] X. Nie, H. Xianyu, R. Lu, T.X. Wu, S.T. Wu, J. Displ. Technol. 3, 280 (2007).

[22] M. Imai, H. Naito, M. Okuda, A. Sugimura, Mol. Cryst. Liq. Cryst. 259, 37 (1995).

[23] X. Quintana, M.A. Geday, B. Cerrolaza, D.P. Medialdea, J.M. Otón, in: Proc. 6th Spanish Conf. on Electronic Devices, San Lorenzo de El Escoria (Madrid, Spain), Madrid 2007, p. 258.

[24] G.D. Lee, J.-H. Son, Y.-H. Choi, J.-J. Lju, K.H. Kim, S.H. Lee, Appl. Phys. Lett. 90, 033509 (2007).

[25] H. Wang, T.X. Wu, X. Zhu, S.T. Wu, J. Appl. Phys. 95, 5502 (2004). 